FEDERAL RESERVE BANK OF SAN FRANCISCO

WORKING PAPER SERIES

\title{
Monetary Policy with Imperfect Knowledge
}

\author{
Athanasios Orphanides \\ Board of Governors of the Federal Reserve System \\ and \\ John C. Williams \\ Federal Reserve Bank of San Francisco
}

October 2005

Working Paper 2005-17

http://www.frbsf.org/publications/economics/papers/2005/wp05-17bk.pdf

The views in this paper are solely the responsibility of the authors and should not be interpreted as reflecting the views of the Federal Reserve Bank of San Francisco or the Board of Governors of the Federal Reserve System. 


\title{
Monetary Policy with Imperfect Knowledge*
}

\author{
Athanasios Orphanides \\ Board of Governors of the Federal Reserve System \\ and \\ John C. Williams \\ Federal Reserve Bank of San Francisco
}

October 2005

\begin{abstract}
We examine the performance and robustness of monetary policy rules when the central bank and the public have imperfect knowledge of the economy and continuously update their estimates of model parameters. We find that versions of the Taylor rule calibrated to perform well under rational expectations with perfect knowledge perform very poorly when agents are learning and the central bank faces uncertainty regarding natural rates. In contrast, difference rules, in which the change in the interest rate is determined by the inflation rate and the change in the unemployment rate, perform well when knowledge is both perfect and imperfect.
\end{abstract}

KEYWORDS: Natural rate of interest, natural rate of unemployment, rational expectations, learning, monetary policy rules.

JEL Classification: E52

*We thank participants of the the 20th Annual Congress of the European Economic Association, Amsterdam, August 24-27, 2005, for useful comments. The opinions expressed are those of the authors and do not necessarily reflect the views of the Board of Governors of the Federal Reserve System or the management of the Federal Reserve Bank of San Francisco. Correspondence: Orphanides: Federal Reserve Board, Washington, D.C. 20551, Tel.: (202) 452-2654, e-mail: Athanasios.Orphanides@frb.gov. Williams: Federal Reserve Bank of San Francisco, 101 Market Street, San Francisco, CA 94105, Tel.: (415) 974-2240, e-mail: John.C.Williams@sf.frb.org. 


\section{Introduction}

Since McCallum (1988) and Taylor (1993), a goal of research on monetary policy design has been to find the characteristics of implementable policy rules that are robust to model misspecification. In this paper, we summarize ongoing research that examines monetary policy design in the presence of imperfect knowledge regarding the structure of the economy on the part of both private agents and the central bank, focusing on two elements that appear especially important for policy design based on past research. The first is policymakers' limited knowledge of the evolution of the natural rates of interest and unemployment in the economy (see Orphanides and Williams (2002) and citations therein). The second is imperfections in expectations formation that arise when economic agents engage in perpetual learning (see Orphanides and Williams (2004) and citations therein).

Recent research has highlighted the ways in which learning can act as a propagation mechanism for macroeconomic disturbances in terms of amplification and persistence. Orphanides and Williams (2005a), for example, show that learning can give rise endogenously to "inflation scares" and can potentially explain the high sensitivity of expectations and asset prices to transitory shocks. In Orphanides and Williams (2005b), we examine the stagflation of the 1970s in the United States in an estimated model with learning. A key finding in that paper is that the interaction of natural rate misperceptions and a monetary policy strategy that emphasized the attainment of full employment undermined the public's confidence in the Fed's commitment to price stability. Absent the endogenous development of beliefs over the period through learning, macroeconomic performance during the 1970s would have been far better.

Learning has also been found to have first-order implications for the design of monetary policy. In Orphanides and Williams (2004, 2005a, 2005c), we show that learning implies a bias towards a more aggressive central bank response to undesired movements in inflation than under rational expectations. Such policies help stabilize inflation expectations near those implied by the rational expectations equilibrium. In addition, in an environment with learning, communicating monetary policy objectives and strategy to the public has the potential to lessen the burden placed on agents to infer central bank intentions. 


\section{An estimated model of the U.S. economy}

For our analysis, we use an estimated quarterly model of the U.S. economy from Orphanides and Williams (2002); details on the specification and estimation of the model are given in that paper. This model allows both for forward-looking determination of prices and unemployment and for the intrinsic inertia that may arise from indexation, habit formation, and other sources. The estimated equations for the inflation rate and the unemployment rate are given by:

$$
\begin{gathered}
\pi_{t}=0.540 \pi_{t+1}^{e}+0.460 \pi_{t-1}-0.341\left(u_{t}^{e}-u_{t}^{*}\right)+e_{\pi, t}, \\
u_{t}=0.257 u_{t+1}^{e}+1.170 u_{t-1}-0.459 u_{t-2}-0.032 u_{t}^{*}+0.043\left(r_{t-1}^{a}-r_{t}^{*}\right)+e_{u, t},
\end{gathered}
$$

with innovation standard errors equal to 1.38 and 0.30 , respectively. Here $\pi$ denotes the annualized log difference of the aggregate output price deflator, $u$ denotes the unemployment rate, $u^{*}$ denotes the (true) natural rate of unemployment, $r^{a}$ denotes the (ex ante) real interest rate with one year maturity, and $r^{*}$ the (true) natural real rate of interest, all in percent. The superscript $e$ denotes the public's expectations formed during $t-1$.

We assume that the true processes governing natural rates in the economy follow highly persistent autoregressive processes with unconditional means given by $\bar{u}^{*}$ and $\bar{r}^{*}$. Specifically, we posit that the natural rates follow:

$$
\begin{aligned}
& u_{t}^{*}=0.01 \bar{u}^{*}+0.99 u_{t-1}^{*}+e_{u^{*}, t}, \\
& r_{t}^{*}=0.01 \bar{r}^{*}+0.99 r_{t-1}^{*}+e_{r^{*}, t} .
\end{aligned}
$$

As discussed in Orphanides and Williams (2002), there exists a wide range of estimates of the variances of the innovations to the natural rates. Indeed, owing to the imprecision in estimates of these variances, the postwar U.S. data do not provide clear guidance regarding these parameters. Therefore, in the following, we consider three alternative calibrations of these variances, which we index by $s$. The case of $s=0$ corresponds to constant and known natural rates, where $\sigma_{e_{u^{*}}}=\sigma_{e_{r^{*}}}=0$. The case of $s=1$ corresponds to the low end of the range of estimates of these variances, for which case we assume $\sigma_{e_{u^{*}}}=0.070$ 
and $\sigma_{e_{r^{*}}}=0.085$. Finally, the case of $s=2$ corresponds to the high end of the range of estimates, for which case we assume $\sigma_{e_{u^{*}}}=0.140$ and $\sigma_{e_{r^{*}}}=0.170$.

We consider two classes of simple monetary policy rules. First, we analyze versions of the "Taylor Rule" (Taylor 1993), where the level of the nominal interest rate is determined by the perceived natural rate of interest, $\hat{r}_{t}^{*}$, the inflation rate, and a measure of the level of the perceived unemployment gap, the difference between the unemployment rate and the perceived natural rate of unemployment, $\hat{u}_{t}^{*}$,

$$
i_{t}=\hat{r}_{t}^{*}+\bar{\pi}_{t+3}^{e}+\theta_{\pi}\left(\bar{\pi}_{t+3}^{e}-\pi^{*}\right)+\theta_{u}\left(u_{t-1}-\hat{u}_{t}^{*}\right) .
$$

We refer to these rules as "level rules" because they relate the level of the interest rate to the level of the unemployment gap. Second, we examine the performance of "difference rules," where the change in the nominal interest rate is determined by the inflation rate and the change in the unemployment rate:

$$
i_{t}=i_{t-1}+\theta_{\pi}\left(\bar{\pi}_{t+3}^{e}-\pi^{*}\right)+\theta_{\Delta u} \Delta u_{t-1}
$$

In Orphanides and Williams (2002), we found that this class of policy rules can perform very well when natural rates are unknown because the setting of policy does not depend at all on estimates of natural rates. For both classes of policy rules, we assume that policy responds to the expected four-quarter inflation rate from $t-1$ to $t+3, \bar{\pi}_{t+3}^{e}$, and that the policymaker's inflation objective, $\pi^{*}$, is zero.

In the case of "level rules," policymakers need a procedure to compute real-time estimates of the natural rates. If policymakers knew the true data-generating processes governing the evolution of natural rates, they could use this knowledge to design the optimal estimator. But, in practice, there is considerable uncertainty about these processes, and the optimal estimator for one process may perform poorly if the process is misspecified. Williams (2005) shows that a simple constant gain method to update natural rate estimates based on the observed rates of unemployment and (ex post) real interest rates is reasonably robust to natural rate model misspecification. We follow this approach and assume that policymakers update their estimates of natural rates using simple constant gain 
estimators given by:

$$
\begin{gathered}
\hat{r}_{t}^{*}=\hat{r}_{t-1}^{*}+0.005\left(i_{t-1}-\pi_{t-1}-\hat{r}_{t-1}^{*}\right), \\
\hat{u}_{t}^{*}=\hat{u}_{t-1}^{*}+0.005\left(u_{t-1}-\hat{u}_{t-1}^{*}\right) .
\end{gathered}
$$

\section{Perpetual Learning}

Expectations play a central role in the determination of inflation, the unemployment rate, and the interest rate in the model. We consider two alternative models of expectations formation. One model, used in most monetary policy research, is rational expectations, that is, expectations that are consistent with the model. The second model is one of perpetual learning, where agents continuously reestimate a forecasting model and form expectations using that model.

In the case of learning, we follow Orphanides and Williams (2005b) and posit that agents obtain forecasts for inflation, unemployment, and interest rates by estimating a restricted VAR of the form corresponding to the reduced form of the rational expectations equilibrium with constant natural rates. We assume that this VAR is estimated recursively with constant gain least squares. Agents use the resulting VAR to construct one-stepahead and multi-step-ahead forecasts each period. This learning model can be justified in two ways. First, in practice agents have only finite quantities of data with which to work, and rational expectations may be seen as an assumption that holds only in the distant future when sufficient data have been collected. Alternatively, agents may allow for the possibility of structural change and therefore place less weight on older data, in which case learning is a never-ending process.

Specifically, let $Y_{t}$ denote the $1 \times 3$ vector consisting of the inflation rate, the unemployment rate, and the federal funds rate, each measured at time $t: Y_{t}=\left(\pi_{t}, u_{t}, i_{t}\right)$, and let $X_{t}$ be the $j \times 1$ vector of a constant and lags of $Y_{t}$ that serve as regressors in the forecast model. For example, in our model, two lags of the unemployment rate and one lag each of inflation and the interest rate suffice to capture the reduced form dynamics under rational expectations with constant natural rates, so $X_{t}=\left(1, \pi_{t-1}, u_{t-1}, u_{t-2}, i_{t-1}\right)^{\prime}$.

The recursive estimation can be described as follows: Let $c_{t}$ be the $j \times 3$ vector of 
coefficients of the forecasting model. Then, using data through period $t$, the parameters for the constant-gain least squares forecasting model can be written as:

$$
\begin{aligned}
c_{t} & =c_{t-1}+\kappa R_{t}^{-1} X_{t}\left(Y_{t}-X_{t}^{\prime} c_{t-1}\right), \\
R_{t} & =\quad R_{t-1}+\kappa\left(X_{t} X_{t}^{\prime}-R_{t-1}\right),
\end{aligned}
$$

where $\kappa>0$ is a small constant gain. We consider three alternative calibrations of the gain, $\kappa=\{0.01,0.02,0.03\}$, based on the results in Orphanides and Williams (2005b) who report that expectations formed with recursive VAR with gains in this range fit those reported in surveys better than higher and lower values of the gain $\kappa$. This learning mechanism represents a relatively modest deviation from rational expectations and yields reasonable forecasts. Indeed, given these values, agents' average forecasting performance in the model is close to the optimal forecast.

We first present some simple comparisons of the behavior of the economy under rational expectations with known natural rates and under learning with time-varying and unobservable natural rates. Under learning, the economy is governed by non-linear dynamics, so we resort to numerical simulations to uncover the properties of the economy, conditional on the policymaker following a specific policy rule. For details on the simulation methodology see Orphanides and Williams (2005c,d). For this purpose, let monetary policy follow a level policy rule with $\theta_{\pi}=0.5$ and $\theta_{u}=-1$. This parameterization is similar to that in the classic Taylor (1993) rule, when Okun's law (with a coefficient of 2) is applied to convert the 0.5 coefficient on the output gap in the classic Taylor rule to a comparable response to the unemployment gap.

Figure 1 compares the impulse responses of inflation and unemployment in our model to one standard deviation shocks in inflation and unemployment under rational expectations with known natural rates (RE) to the impulse responses under imperfect knowledge with time variation in the natural rates, $s=1$, and perpetual learning with gain $\kappa=0.02$. Each period corresponds to one quarter. Under learning, the impulse responses to a specific shock vary with the state of the economy $X$ and the state of beliefs governing the formation of expectations, $c$ and $R$. Depending on the initial conditions, $\{X, c, R\}$, the response to any given shock differs. To summarize the range of possible outcomes in the figure, we plot the 

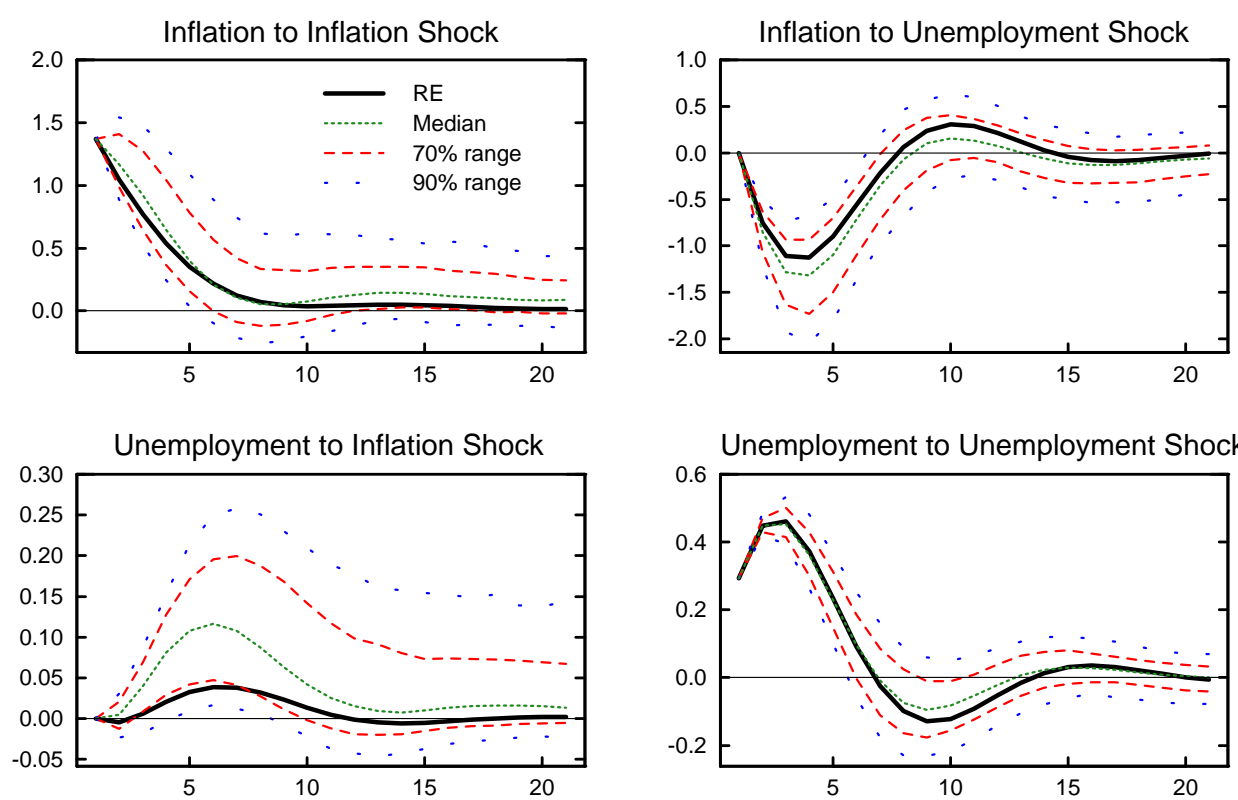

Figure 1: Impulse Responses with rule: $i_{t}=\hat{r}_{t}^{*}+\bar{\pi}_{t+3}^{e}+0.5\left(\bar{\pi}_{t+1}^{e}-\pi^{*}\right)-\left(u_{t-1}-\hat{u}_{t}^{*}\right)$. Rational expectations with perfect knowledge (RE), and median and $70 \%$ and $90 \%$ ranges of outcomes under learning with $s=1, \kappa=0.02$.

median and $70 \%$ and $90 \%$ ranges of the distribution of impulse responses corresponding to the stationary distribution of $\{X, c, R\}$. Under rational expectations, the responses are invariant to the state of the economy.

The dynamic impulse responses to a specific shock exhibit considerable variation under learning. Further, the distribution of responses is not symmetric around the impulse response that obtains under rational expectations. For example, the impulse responses of inflation and unemployment to an inflation shock are noticeably skewed in a direction that yields greater persistence. Comparison of the upper envelope of the $70 \%$ and $90 \%$ ranges indicates that with a small probability this persistence may be quite extreme, showing that under learning the inflation expectations process can become unmoored for an extended period. (See Orphanides and Williams (2004) for a more detailed discussion of the implications of learning for economic dynamics.)

Overall, perpetual learning provides a powerful propagation mechanism for economic shocks in the economy, resulting in greater volatility and persistence. With the rule examined here, the standard deviation of the unemployment gap rises from 0.87 percent under rational expectations with constant natural rates to 1.11 percent under learning with $s=1$ 

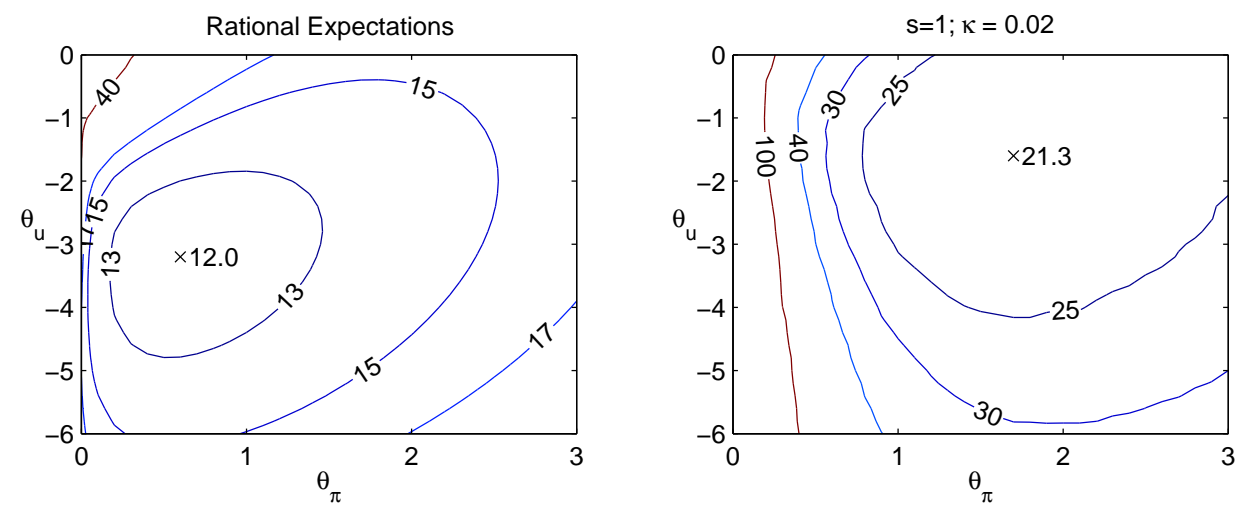

Figure 2: Performance of Level Rule. $i_{t}=\hat{r}_{t}^{*}+\bar{\pi}_{t+3}^{e}+\theta_{\pi}\left(\bar{\pi}_{t+3}^{e}-\pi^{*}\right)+\theta_{u}\left(u_{t-1}-\hat{u}_{t}^{*}\right)$

and $\kappa=0.02$. For inflation, the increase in the standard deviation is even more dramatic, from 2.93 percent to 4.35 percent. Similarly, the first-order autocorrelation of the unemployment gap rises from 0.88 to 0.92 and that of inflation rises from 0.81 to 0.90 .

\section{Implications for Monetary Policy Design}

Acknowledging that expectations formation may exhibit imperfections associated with learning and that policymakers may have limited knowledge regarding the evolution of natural rates in the economy has potentially significant implications for monetary policy design. Let the policymakers' objective be to minimize the weighted sum of the unconditional variances of inflation, the unemployment gap, and the change in the nominal federal funds rate:

$$
\mathcal{L}=\operatorname{Var}\left(\pi-\pi^{*}\right)+\lambda \operatorname{Var}\left(u-u^{*}\right)+\nu \operatorname{Var}(\Delta(i))
$$

where $\operatorname{Var}(x)$ denotes the unconditional variance of variable $x$. As a benchmark, we consider $\lambda=4$ and $\nu=1$. Note that this $\lambda$ corresponds to equal weights on inflation and output gap variability - from Okun's law.

Figure 2 presents iso-loss contours of the economy with the above loss function for alternative parameterizations of the level rule. The left panel shows the loss under rational expectations with constant natural rates, referred to in the following as "perfect knowledge," while the right shows the loss under learning and time-varying natural rates. Figure 3 presents similar iso-loss contours corresponding to the difference rule. In each panel, the coordinates corresponding to the minimum loss (marked with an " $\mathrm{x}$ ") identify the optimal 

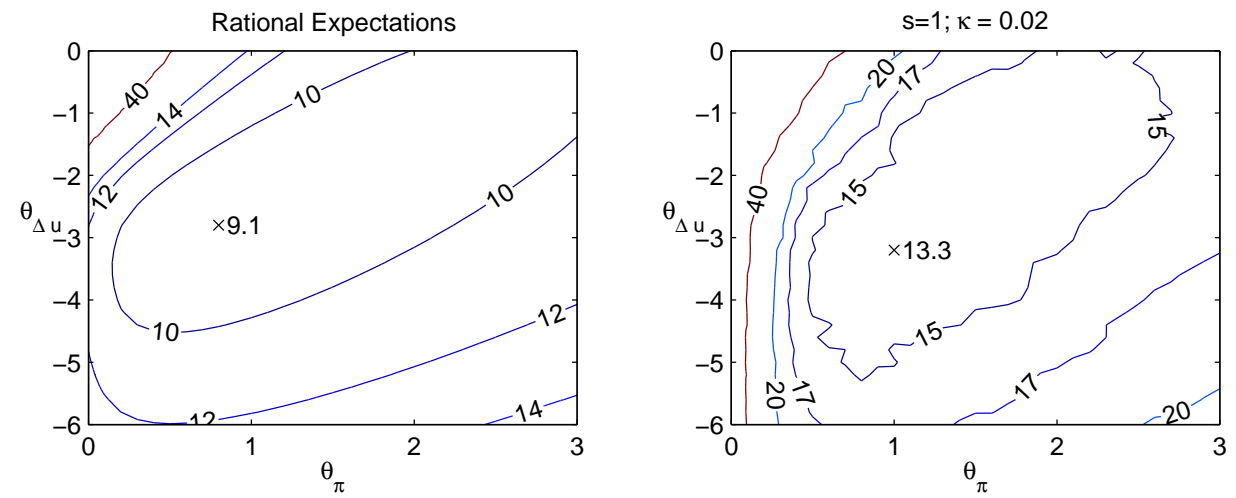

Figure 3: Performance of Difference Rule. $i_{t}=i_{t-1}+\theta_{\pi}\left(\bar{\pi}_{t+1}^{e}-\pi^{*}\right)+\theta_{\Delta u} \Delta u_{t-1}$

parameters for the underlying rule. Thus, from Figure 2, the optimal level rule under perfect knowledge is given by: $i_{t}=\hat{r}_{t}^{*}+\bar{\pi}_{t+3}^{e}+0.6\left(\bar{\pi}_{t+3}^{e}-\pi^{*}\right)-3.2\left(u_{t-1}-\hat{u}_{t}^{*}\right)$, and from Figure 3 , the optimal difference rule is: $i_{t}=i_{t-1}+0.9\left(\bar{\pi}_{t+3}^{e}-\pi^{*}\right)-2.7 \Delta u_{t-1}$.

The level rule optimized under the assumption of perfect knowledge is not robust to uncertainty regarding the formation of expectations or natural rate variation. As seen by comparing the two panels in Figure 2, if the optimal level policy under perfect knowledge were implemented when the economy is governed by $s=1$ and $\kappa=0.02$, the loss would be very high. One problem with this particular policy rule is that policymaker misperceptions of the natural rates of interest and unemployment translate into persistent overly expansionary or contractionary policy mistakes. In such circumstances, the policy rule's rather timid response to inflation is insufficient to contain inflation expectations near the policymaker's target. The optimal policy under learning is quite different: it is much more responsive to inflation and considerably less responsive to the perceived unemployment gap. Based on this comparison, for level rules of this type, there is a significant tradeoff between achieving optimal performance in one model specification and being robust to model misspecification.

In sharp contrast to the level rule optimized assuming perfect knowledge, the difference rule optimized assuming perfect knowledge appears to be robust to learning and natural rate variation, as seen in Figure 3. A difference rule with a response coefficient to inflation of about 1 and to the change in the unemployment rate of about -3 is nearly optimal in both model specifications, and the loss surface is reasonably flat in that region.

We now formalize the search for a robust monetary policy rule by computing the op- 
timal Bayesian policy rules where the policymaker is assumed to have priors over a set of specifications of learning processes and degrees of natural rate variation. Specifically, suppose that the policymaker has a flat prior on the 12 models corresponding to the various combinations of the three possible values of $s=\{0,1,2\}$, and four models for expectations: rational expectations and learning with values $\kappa=\{0.01,0.02,0.03\}$.

The resulting optimal Bayesian level rule is given by: $i_{t}=\hat{r}_{t}^{*}+\bar{\pi}_{t+3}^{e}+1.6\left(\bar{\pi}_{t+3}^{e}-\right.$ $\left.\pi^{*}\right)-1.7\left(u_{t-1}-\hat{u}_{t}^{*}\right)$. This rule differs markedly from the optimal level rule under perfect knowledge in that the response to inflation is much larger and the response to the perceived unemployment gap is much smaller. The optimized Bayesian difference rule is given by: $i_{t}=i_{t-1}+1.1\left(\bar{\pi}_{t+3}^{e}-\pi^{*}\right)-2.6 \Delta u_{t-1}$, which is virtually identical to the difference rule optimized under the assumption of perfect knowledge.

A summary comparison of the losses associated with each optimized Bayesian rule is presented in Table 1. The table has a row for each of the various combinations of $s$ and $\kappa$. Under the columns $\mathcal{L}_{L}^{R E}$ and $\mathcal{L}_{D}^{R E}$, we note the loss associated with the rules optimized assuming perfect knowledge. Under the columns $\mathcal{L}_{L}^{B}$ and $\mathcal{L}_{D}^{B}$, we report the losses associated with the optimized Bayesian policies. The columns $\mathcal{L}_{L}^{*}$, and $\mathcal{L}_{D}^{*}$, show the loss associated with the optimized policies for the particular model in each row-which could be adopted if a policymaker knew the true model with certainty.

The table confirms the robustness of the difference rule and its dominance over the level rule. Indeed, the performance of the Bayesian difference rule is quite remarkable in this model. The loss from adopting it versus a rule optimized for the specific model shown in each row is negligible for most models and quite modest even under the worst possible case $(s=2$ and $\kappa=0.03)$.

\section{Conclusion}

This paper has highlighted the implications of imperfect knowledge for the design of robust monetary policy. A key finding in this literature is that monetary policy rules that perform well under the assumption of perfect knowledge may perform very poorly with relatively modest deviations from rational expectations and with the assumption that natural rates 
Table 1. Performance of Optimal Bayesian Rules

\begin{tabular}{|c|c|c|c|c|c|c|c|}
\hline \multirow[b]{2}{*}{ Expectations } & \multirow[b]{2}{*}{$s$} & \multicolumn{3}{|c|}{ Level Rule } & \multicolumn{3}{|c|}{ Difference Rule } \\
\hline & & $\mathcal{L}_{L}^{R E}$ & $\mathcal{L}_{L}^{*}$ & $\mathcal{L}_{L}^{B}$ & $\mathcal{L}_{D}^{R E}$ & $\mathcal{L}_{D}^{*}$ & $\mathcal{L}_{D}^{B}$ \\
\hline \multirow[t]{3}{*}{$R E$} & 0 & 12.0 & 12.0 & 13.5 & 9.1 & 9.1 & 9.1 \\
\hline & 1 & 17.7 & 13.6 & 13.8 & 9.2 & 9.2 & 9.2 \\
\hline & 2 & 34.7 & 14.9 & 15.0 & 9.6 & 9.5 & 9.5 \\
\hline \multirow[t]{3}{*}{$\kappa=0.01$} & 0 & 16.2 & 15.0 & 15.8 & 11.1 & 10.6 & 10.7 \\
\hline & 1 & 35.0 & 19.6 & 19.8 & 11.9 & 11.8 & 11.8 \\
\hline & 2 & 60.5 & 23.9 & 25.2 & 14.4 & 14.2 & 14.3 \\
\hline \multirow[t]{3}{*}{$\kappa=0.02$} & 0 & 19.6 & 17.5 & 18.5 & 12.5 & 12.2 & 12.3 \\
\hline & 1 & 36.2 & 21.3 & 21.4 & 14.0 & 13.3 & 13.6 \\
\hline & 2 & 66.3 & 25.6 & 26.6 & 16.6 & 15.5 & 15.8 \\
\hline \multirow[t]{3}{*}{$\kappa=0.03$} & 0 & 21.9 & 19.6 & 20.9 & 15.3 & 14.0 & 14.2 \\
\hline & 1 & 38.4 & 23.1 & 23.5 & 16.7 & 15.1 & 15.3 \\
\hline & 2 & 70.0 & 28.0 & 28.2 & 18.2 & 17.4 & 18.3 \\
\hline Mean loss & & 35.7 & 19.5 & 20.2 & 13.2 & 12.6 & 12.8 \\
\hline
\end{tabular}

Notes: Level Rule: $i_{t}=\hat{r}_{t}^{*}+\bar{\pi}_{t+3}^{e}+\theta_{\pi}\left(\bar{\pi}_{t+3}^{e}-\pi^{*}\right)+\theta_{u}\left(u_{t-1}-\hat{u}_{t}^{*}\right) . \mathcal{L}_{L}^{R E}$ corresponds to RE-optimal rule, $\theta_{\pi}=0.6, \theta_{u}=-3.2$. $\mathcal{L}_{L}^{B}$ corresponds to optimal Bayesian rule, $\theta_{\pi}=1.6, \theta_{u}=-1.7 . \mathcal{L}_{L}^{*}$ is minimum possible loss for model in row. Difference rule: $i_{t}=i_{t-1}+\theta_{\pi}\left(\bar{\pi}_{t+3}^{e}-\pi^{*}\right)+\theta_{\Delta u} \Delta u_{t-1}$. $\mathcal{L}_{D}^{R E}$ corresponds to RE-optimal rule, $\theta_{\pi}=0.9, \theta_{\Delta u}=-2.7 . \mathcal{L}_{D}^{B}$ corresponds to RE-optimal rule, $\theta_{\pi}=1.1, \theta_{\Delta u}=-2.6$. $\mathcal{L}_{D}^{*}$ is minimum possible loss for model in row.

are known. A more positive finding is that in our estimated hybrid model of the U.S. economy, a difference specification of a monetary policy rule is robust to misspecification of the processes of expectations formation and the generation of natural rates. This analysis abstracts from other aspects of model uncertainty. Further research into the robustness characteristics of simple rules under imperfect knowledge is a fruitful way to make progress towards avoiding costly policy mistakes.

\section{References}

McCallum, Bennett T. (1988). "Robustness Properties of a Rule for Monetary Policy." Carnegie-Rochester Conference Series on Public Policy, 29, 173-203.

Orphanides, Athanasios and John C. Williams (2002). "Robust Monetary Policy Rules with Unknown Natural Rates." Brookings Papers on Economic Activity, 2:2002, 63-118.

Orphanides, Athanasios and John C. Williams (2004). "Imperfect Knowledge, Inflation Expectations and Monetary Policy." In The Inflation Targeting Debate, edited by Ben Bernanke and Michael Woodford, University of Chicago Press.

Orphanides, Athanasios and John C. Williams (2005a). "Inflation Scares and Forecast- 
Based Monetary Policy." Review of Economic Dynamics, 8, 498-527.

Orphanides, Athanasios and John C. Williams (2005b). "The Decline of Activist Stabilization Policy: Natural Rate Misperceptions, Learning, and Expectations." Journal of Economic Dynamics and Control.

Orphanides, Athanasios and John C. Williams (2005c). "Imperfect Knowledge, Inflation Expectations and Monetary Policy." Working paper.

Orphanides, Athanasios and John C. Williams (2005d). "Inflation Targeting under Imperfect Knowledge." Working paper.

Taylor, John B. (1993). "Discretion versus Policy Rules in Practice." Carnegie-Rochester Conference Series on Public Policy, 39, 195-214.

Williams, John C. (2005). "Robust Estimation and Monetary Policy with Unobserved Structural Change." In Models and Monetary Policy: Research in the Tradition of Dale Henderson, Richard Porter and Peter Tinsley, edited by Jon Faust, Athanasios Orphanides and David L. Reifschneider. Board of Governors of the Federal Reserve System, forthcoming. 